\title{
AS FACULDADES DE TECNOLOGIA DO ESTADO DE SÃO PAULO: ATRIBUINDO SIGNIFICADOS À EDUCAÇÃO TECNOLÓGICA E À FORMAÇÃO DE SEUS PROFESSORES DE MATEMÁTICA
}

\section{THE FACULITIES OF TECHNOLOGY OF SÃO PAULO STATE - BRAZIL: ASSIGNING MEANINGS TO TECHNOLOGICAL EDUCATION AND ITS FORMATION MATHEMATICS TEACHERS}

\author{
Rosemeiry de Castro Prado ${ }^{1}$ \\ Antonio Vicente Marafioti Garnica ${ }^{2}$
}

\begin{abstract}
Resumo: O principal foco deste trabalho está nas Faculdades de Tecnologia do estado de São Paulo (Fatec), sua história e as práticas nelas desenvolvidas por professores de Matemática para o ensino dessa disciplina. Tendo como principal aporte metodológico os princípios da História Oral, o estudo perpassa questões que envolvem os pressupostos metodológicos; as fontes narrativas que dão sustentação às compreensões resultantes das análises; uma história da Fatec e alguns aspectos das práticas relativas ao ensino e aprendizagem de Matemática nessa instituição, focando mais detidamente as décadas de 1970 a 1990. Por meio das narrativas orais, percebe-se que, ainda hoje, há um forte discurso de que a educação tecnológica deve ser diferente das demais e, deste modo, sobrevive nas Fatec a bandeira de que os aprendizados que interessam aos cursos são aqueles destinados ao mundo do trabalho, criando-se, muitas vezes, estratégias metodológicas e materiais de estudo para as disciplinas.
\end{abstract}

Palavras-chave: Educação Matemática; Educação Tecnológica; História Oral; Fatec.

\begin{abstract}
The main focus of this work lies in the Faculties of Technology of São Paulo State (Fatec), the history of such institution and the practices developed by its Math teachers. Having as main methodological support the principles of Oral History, the study goes through issues involving methodological assumptions, the narrative sources that support the understandings that come from the analysis of these narrative and other sources, a history of Fatec and some aspects of practices related to teaching and learning mathematics in this institution, focusing more closely on the 1970s and 1990s. Through oral narratives, it is clear that, even today, there is a strong discourse that technological education must be different from the others and, in this way, the banner survives in Fatec that the lessons that interest the courses are those aimed at the world of work, often creating methodological strategies and study materials for the disciplines.
\end{abstract}

Keywords: Mathematical Education; Technological Education; Oral History; Fatec.

\section{Introdução}

Tendo como guia a plausibilidade, além dos procedimentos e fundamentos propostos pela metodologia da História Oral para construir uma versão historiográfica, o trabalho aqui relatado teve a intenção de contar uma história sobre as Faculdades de Tecnologia do estado de São Paulo (Fatec) enfatizando, nessa história, a trajetória e a

\footnotetext{
${ }^{1}$ Doutora em Educação para a Ciência (UNESP). Faculdade de Tecnologia do Estado de São Paulo (Fatec/ Ourinhos). São Paulo, Brasil. E-maiil: rose.prado@fatecourinhos.edu.br

2 Doutor em Educação Matemática (UNESP). Universidade Estadual Paulista "Júlio de Mesquita Filho" (UNESP/Bauru). São Paulo, Brasil. E-mail: vicente.garnica@unesp.br
} 
atuação de professores de Matemática. Inscreve-se, portanto, a investigação, no campo da História da Educação Brasileira, mais especificamente, no campo da História da Educação Matemática no Brasil.

Ultrapassando a concepção positivista dos fatos, a importância exacerbada dada aos documentos escritos e às fontes ditas "primárias" e a quimera de promover um resgate de fatos definitivos, a pesquisa realizada não deixa de considerar nenhuma fonte que o discurso historiográfico nos ensinou a respeitar. A historiografia defendida neste trabalho caminha ao encontro das pesquisas realizadas no âmbito do Grupo História Oral e Educação Matemática - Ghoem -, buscando construir significados a partir de distintas e variadas narrativas acerca do que se quer conhecer.

Para compor a narrativa deste trabalho, contamos com narrativas de oito professores que atuaram/atuam nas Faculdades de Tecnologia do estado de São Paulo.

Quadro 1: Relação das entrevistas

\begin{tabular}{|c|c|c|c|}
\hline ENTREVISTADO & DATA & DURAÇÃO & LOCAL \\
\hline $\begin{array}{l}\text { Paulo Henriques Chixaro } \\
\text { Mestre em Engenharia Naval e Oceânica pela } \\
\text { USP, no ano de } 2003 \text {. Atualmente é professor da } \\
\text { Fatec Ourinhos, SP. }\end{array}$ & $16 / 03 / 2016$ & $57 \mathrm{~min} 13 \mathrm{~s}$ & Ourinhos \\
\hline $\begin{array}{l}\text { Vera Lúcia Silva Camargo } \\
\text { Graduada em Processamento de Dados, pelo } \\
\text { CEETPS (1977-1978) }\end{array}$ & $27 / 07 / 2016$ & $1 \mathrm{~h} 16 \mathrm{~min} 50 \mathrm{~s}$ & Ourinhos \\
\hline $\begin{array}{l}\text { Sidney Carlos Ferrari } \\
\text { Doutor em Engenharia de Produção, pela UFScar, } \\
\text { em São Carlos, interior de São Paulo (2016). }\end{array}$ & $16 / 09 / 2016$ & $33 \min 36 s$ & Ourinhos \\
\hline $\begin{array}{l}\text { Walter Paulette } \\
\text { Doutor pela Unesp - Rio Claro em Educação } \\
\text { Matemática (2003). }\end{array}$ & $23 / 11 / 2016$ & $51 \mathrm{~min} 51 \mathrm{~s}$ & São Paulo \\
\hline $\begin{array}{l}\text { Ayrton Barboni } \\
\text { Mestre em Matemática pela Pontifícia } \\
\text { Universidade Católica de São Paulo, PUC-SP } \\
\text { (1983). }\end{array}$ & $23 / 11 / 2016$ & $51 \mathrm{~min} 51 \mathrm{~s}$ & São Paulo \\
\hline $\begin{array}{l}\text { Jaques Vereta } \\
\text { Mestre em Matemática pela Pontifícia } \\
\text { Universidade Católica de São Paulo (2000). }\end{array}$ & $06 / 12 / 2016$ & 1h09min & São Paulo \\
\hline $\begin{array}{l}\text { Katsuyohi Kurata } \\
\text { Mestre em Tenologia em Gestão, } \\
\text { Desenvolvimento e Formação, pelo Centro } \\
\text { Estadual de Educação Tecnológica Paula Souza, } \\
\text { CEETEPS (2007). }\end{array}$ & $07 / 12 / 2016$ & $1 \mathrm{~h} 30 \mathrm{~min} 49 \mathrm{~s}$ & São Paulo \\
\hline $\begin{array}{l}\text { Suzana Abreu de Oliveira Souza } \\
\text { Doutora em Matemática Aplicada na USP (2001) }\end{array}$ & $07 / 12 / 2016$ & $33 \mathrm{~min}$ & São Paulo \\
\hline
\end{tabular}

Fonte: Autora (2017)

Nossos colaboradores são quase todos professores de Matemática que iniciaram suas carreiras nessas instituições e que, de algum modo, vivenciaram o ambiente da Fatec São Paulo, "paradigma” de todas as unidades hoje existentes. 
A história que trata das Faculdades de Tecnologia do estado de São Paulo e dos professores de Matemática que nela atuam, apoia-se num contexto construído em meio ao exame hermenêutico de variadas narrativas - escritas, orais ou iconográficas acessadas ou criadas.

Posto que a noção de origem implica um retrocesso infinito, a origem-começo arbitrada para a narrativa sobre as Faculdades de Tecnologia do estado de São Paulo e seus professores de Matemática foi por nós situada nas décadas de 1970, 1980 e 1980, ainda que tenha sido necessário romper essas fronteiras temporais em alguns momentos.

As entrevistas, em muitos momentos, aparecem como pontas de icebergs que revelam e disparam elementos que, em comum, dizem da necessidade de, à época da criação da instituição, suprir o mercado com mão de obra diferente das existentes até então, do que decorre a necessidade de formar um profissional intermediário entre o engenheiro e o técnico, assumindo, muitas vezes, a expectativa de uma formação que visaria atingir o almejado desenvolvimento econômico de que o país necessitava.

\section{Breves considerações sobre história oral e narrativas}

A História Oral utilizada em nosso trabalho preconiza dialogar com fontes de várias naturezas, exercitando a diversidade de interpretações e abraçando uma proposta de configuração coletiva, descentralizada e dinâmica, focando-se nas narrativas criadas a partir da oralidade de sujeitos que são entrevistados visando a (re)criar cenários plausíveis do passado, no caso, relativos à atuação e à formação de professores que atuaram (alguns ainda hoje atuam) nas Faculdades de Tecnologia do estado de São Paulo. Assim, é nas narrativas que se concentra o núcleo do processo de aproximação com o fazer historiográfico proposto nesta investigação:

\footnotetext{
Narrativas orais são fontes historiográficas. Para servir a pesquisas, narrativas orais usualmente são registradas por escrito devido à durabilidade do suporte e à facilidade de manuseio. Narrativas orais tornadas narrativas escritas são fontes historiográficas. A História Oral é um modo de produzir narrativas orais e com essa finalidade tem sido mobilizada por inúmeros agentes, dentro e fora da academia, sendo praticada, por exemplo, tanto por "pessoas comuns" como por historiadores "de ofício" e pesquisadores dos mais distintos campos. Na academia, a História Oral ganha contornos mais rígidos, inscreve-se numa determinada ordem de discurso, e passa a ser vista como metodologia de pesquisa e até mesmo como "metodologia de pesquisa de abordagem qualitativa" (GARNICA, 2013, p. 54).
}

Neste sentido, uma série de procedimentos compõe nossa abordagem metodológica: inicialmente, fizemos contato com os depoentes (colaboradores), 
registramos cuidadosamente as entrevistas feitas e, junto a outras fontes buscamos, hermeneuticamente, um sentido para essas tantas narrativas, sempre tendo como norte nossa questão de pesquisa, que, a priori, não foi dotada de nenhum roteiro fixo e comum a todas as entrevistas: estabelecemos algumas perguntas-chave, geralmente abertas, direcionadas a compreender nosso tema específico.

Os depoimentos, alguns gravados, alguns filmados e outros, gravados e filmados, passaram por um processo chamado transcrição, que constitui um primeiro registro escrito dos depoimentos orais, sendo o pesquisador o mais fiel possível aos diálogos ocorridos entre pesquisadora e colaboradores. Os depoimentos transcritos passam, posteriormente, pelo momento de textualização, gerando um texto - que pode conter edições, correções, alterações textuais que evitem repetições e vícios da linguagem oral, por exemplo - com o qual o entrevistado concorda e no qual se reconhece. Aos colaboradores, após um processo de leituras, acertos e negociações acerca do registro escrito da entrevista, foram solicitadas cartas de cessão para que se pudéssemos tornar públicos esses registros. As cartas foram assinadas e entregues pelo correio ou, digitalizadas, remetidas por email.

Em síntese, e reiterando nosso posicionamento quanto à metodologia que guiou essa nossa investigação: apostamos na História Oral. Apostar na História Oral, é importante frisar, de modo algum implica desprezar outras fontes, e essa disposição de valer-se de tantas fontes quantas forem possíveis criar ou juntar, é ainda mais essencial quando se parte da disposição - como é o nosso caso - de usar a História Oral num trabalho cuja natureza é assumidamente historiográfica.

A narrativa oral tornada escritura apresentou-se como núcleo da investigação, posto que acreditamos ser possível, com a História Oral, esclarecer trajetórias individuais, eventos ou processos que às vezes não têm como ser entendidos ou elucidados de outra forma, gerando documentos (entrevistas) que possuem uma característica singular: elas são o resultado do diálogo entre entrevistador e entrevistado, entre sujeito e "objeto" de estudo (CURY, 2011). Ao mesmo tempo, documentos escritos, como as apostilas criadas pelos professores da Fatec São Paulo, documentos, legislações, cartilhas do Sindicato dos Trabalhadores do Centro Paula Souza, artigos em revistas e livros de tecnologia, sugeridos ou não pelas entrevistas, foram coletados e estudados.

Neste sentido, nossas entrevistas podem trazer à cena detalhes da estruturação e do funcionamento das faculdades de tecnologia em seus diversos aspectos a partir das vozes, das experiências e da sensibilidade de nossos depoentes. Por meio das narrativas 
surge a possibilidade de se pensar na atuação e formação dos professores de Matemática nas décadas de 1970, 1980 e 1990 em tais instituições, e em como fatores externos, políticos e sociais interferiram de modo direto na implantação e desenvolvimento do Centro Paula Souza. Trata-se de criar, no presente, significados para as (e a partir das) vivências de pessoas que, familiares ao campo que pretendemos estudar - as Fatec aceitaram colaborar conosco.

Não se entende plausivelmente o passado apenas a partir da "história oficial", tampouco como uma coleção de recordações do passado buscando sua reprodução exata. Toda essa (re) criação do passado é feita a partir do presente, daquilo que se recorda, do que se tem, hoje, como importante para compreender as coisas, ou seja, as recordações advindas da consciência coletiva de um grupo (ou do indivíduo) podem modificar a percepção do passado em função das circunstâncias presentes (BOLÍVAR; DOMINGO; FERNÁNDEZ, 2001).

Assim, se apenas resíduos não nos permitem o todo da operação historiográfica, esses registros orais são fundamentais para que as perspectivas singulares dos sujeitos fiquem registradas e apoiem o movimento de compreender aquilo que pretendemos compreender.

O pensar histórico, aqui, se apoia na defesa da perspectiva de que o conhecimento pode emergir da escuta atenta à voz do outro que, em sua subjetividade (da qual não pode se apartar), dispara elementos que podem ser confrontados, complementados, cotejados, analisados e reanalisados, permitindo que caminhemos a partir do diálogo com o outro ainda que os pontos de vista enunciados possam ser ou parecer contraditórios.

"Dialogar" com fontes de várias naturezas além das orais (como as escritas e digitais), exercitar a pluralidade de interpretações, considerar o trabalho coletivo, apresentar propostas eticamente comprometidas e cuidadosamente elaboradas, dominar a produção de narrativas, negar a objetividade científica e conceber a invenção plausível do passado como função da historiografia, repensando a neutralidade do pesquisador em relação ao pesquisado, afastando-se da perspectiva historiográfica positivista são alguns pressupostos que conduzem as pesquisas realizadas no Ghoem.

Como se percebe, a História Oral, possibilita, dentre vários outros aspectos, criar fontes para disparar e apoiar o trabalho investigativo do pesquisador. As narrativas que os colaboradores compartilham conosco, o modo como eles, depoentes, se constituem a si próprios como narradores, passam a fazer parte indissociável do cenário da pesquisa, e são o fermento essencial para que uma narrativa historiográfica possa ser criada. 


\section{Era uma vez ...}

Era uma vez um país em que as pessoas foram proibidas de pensar, falar e fazer o que queriam. Era uma vez um país onde muita gente ficava presa e as crianças eram privadas de seus pais. Era uma vez uma história triste que ninguém gosta de ouvir, mas que precisa ser lembrada, contada e recontada para nunca se repetir (BRASIL, 2009).

Logo, houve esse tempo e esse contexto que se iniciou na década de 1960. Hoje, passados mais de cinquenta anos, ele tem sido revisitado por pesquisadores das mais diversas procedências e áreas, matizando, nas interpretações recentes, algumas das interpretações criadas no passado.

A década de 1960 foi marcada no Brasil por taxas de urbanização e de crescimento demográfico que davam indícios do desenvolvimento e da necessidade de modernização do país.

Modernizar - esse um dos principais discursos à época - era também uma necessidade urgente para que se combatesse a ameaça comunista que poderia ser instalada de modo fácil em países subdesenvolvidos como o Brasil. Mas, como fazer a modernização? A modernização tão almejada focava setores prioritários como a educação, responsável por efeitos multiplicadores e disseminadores de valores nos jovens que frequentavam as nossas instituições de ensino. Para que pudessem aflorar ideologias julgadas democráticas que iriam garantir o afastamento de quaisquer possibilidades de tendências como a marxista e a comunista, a modernização nos países pobres ia além do progresso econômico e desenvolvimentista.

Desse ponto de vista, as mudanças políticas e culturais faziam-se necessárias, bem como a modernização das instituições educacionais brasileiras, principalmente as universidades, pois eram os locus de treinamento de mão de obra qualificada, de líderes e de formação de opiniões.

Apesar do consenso de que a universidade brasileira nos anos 1960 havia herdado uma estrutura que se tornara arcaica, não atendendo à demanda dos jovens com condições de acesso ao ensino superior, divergências vigoravam em torno das mudanças necessárias e, muitas vezes, atribuía-se à esfera política e aos professores catedráticos a culpa pela carência de uma produção científica que poderia gerar transformações sociais populares nas faculdades, oferecendo cursos noturnos, além das campanhas de alfabetização e de cultura popular (MOTTA, 2014). 
Assim, ao revisitarmos, por exemplo, o final da década de 1960 e início da década de 1970, período marcado por discussões no interior das universidades sobre o excesso teórico e a duração dos cursos de graduação que afastavam os jovens do mercado de trabalho, encontramos um país mergulhado num momento intenso de grandes investimentos e, especialmente, o estado de São Paulo, contando com um notável parque industrial, demandava pessoal qualificado para atuar na indústria. Era então urgente a criação de cursos que atendessem às várias atividades de produção, o que levava à aposta do governo paulista de criar instituições que pudessem modernizar a sociedade por meio da tecnologia e da pesquisa.

Efetivamente, em 1969, os cursos superiores de tecnologia com duração de dois ou três anos foram implantados. Uma autarquia para articular e desenvolver a formação de tecnólogos foi criada e recebeu, em princípio, o nome de Centro Estadual de Educação Tecnológica de São Paulo (CEET). Suas bases estavam fincadas nos cursos tecnológicos estrangeiros, no Instituto Tecnológico da Aeronáutica (ITA), em São José dos Campos, e nos cursos de Engenharia de Produção da Faculdade de Engenharia Industrial (FEI), de São Bernardo do Campo (MOTOYAMA, 1995). Contudo, as Fatec também podem ter recebido a influência de faculdades de outros países, como as Fachhochschulen, na Alemanha.

\begin{abstract}
São Paulo crescia muito na época da criação das Faculdades de Tecnologia do estado de São Paulo e quanto aos modelos pelos quais perpassou o da Fatec, existe um parecer, o do Cordão, Francisco Cordão, que ajuda a compreender a organização, a regulamentação dos cursos de tecnologia para o restante do país. Ele conversou muito comigo no Centro Paula Souza e eu me lembro bastante das idas dele ao Centro, sempre levando sua experiência de Senac, que também abrangia alguns cursos nessa linha, e ele traça uma história também bem interessante. Ele falava do modelo inglês, de seus cursos de três anos e mencionava também os modelos franceses e alemães. Eu não participei do processo inicial de implantação do Centro em 1969, mas eu acredito que quem, na época, estabeleceu esses cursos conhecia esses modelos, tanto é que Paula Souza é o nome de um senhor que foi estudar nas Fachhochschulen, da Alemanha, no final do século retrasado. Ele foi um estudante de uma dessas Fachhochschulen, então tivemos influências de outros países, senão, qual seria a razão do nome Paula Souza? (Depoimento da professora Vera, nesta pesquisa).
\end{abstract}

O Centro Estadual de Educação Tecnológica de São Paulo iniciou suas atividades em 19 de maio de 1970, como autarquia vinculada administrativamente à Secretaria de Estado dos Negócios da Educação e financeiramente à Secretaria da Fazenda. A primeira aula foi ministrada no dia 20 de julho do mesmo ano. Foi em 20 de maio de 1970 que se criou a Faculdade de Tecnologia de Sorocaba, subordinada à Coordenadoria do Ensino Técnico da Secretaria da Educação de São Paulo, tendo sido também criados os três 
primeiros cursos na área de construção civil do CEET em São Paulo, nas modalidades Movimento de Terra e Pavimentação; Obras Hidráulicas e de Edifícios, além de dois cursos na área de mecânica, em Sorocaba: Desenhista Projetista e Oficinas (SILVA, 2008). Os cinco cursos se reuniram em uma faculdade de tecnologia - a Faculdade de Tecnologia de São Paulo. Em 1973, a capital ganhou a Fatec São Paulo, que iniciou suas atividades no antigo prédio da Escola Politécnica da USP, e mais um curso foi criado, o de Tecnólogo em Soldagem. No ano seguinte, criou-se o curso de Tecnólogo em Processamento de Dados (TAIRA, 2005).

A Lei nº 952 de 30.01.1976 criou a Universidade Estadual Paulista "Júlio de Mesquita Filho", Unesp, com a incorporação dos Institutos Isolados de Ensino Superior do estado de São Paulo, então unidades universitárias situadas em diferentes pontos do interior paulista. Pela mesma Lei, em seu Artigo 15, o Centro Estadual de Educação Tecnológica Paula Souza (CEETEPS) foi então transformado em autarquia de regime especial associada à Universidade.

O recorte temporal pelo qual transitamos neste nosso trabalho privilegia alguns aspectos que podem trazer elementos para uma breve história da instituição aqui pesquisada. As décadas de 1970, 1980 e 1990 marcaram não somente períodos distintos no cenário cultural, social e econômico do país, mas também, quanto às faculdades sobre as quais focamos nossos olhares, emergiram objetivos e finalidades que se diferenciaram à medida que os protagonistas da criação, da implantação e do desenvolvimento das Faculdades de Tecnologia do Centro Paula Souza projetaram suas ações, concepções e expectativas no entorno do ensino tecnológico no estado de São Paulo.

Tratamos de um centro educacional que hoje agrega mais de setenta faculdades de tecnologia espalhadas no estado de São Paulo, mas contemplamos, de modo mais focado, duas de suas instituições nas quais nossos depoentes circularam (e ainda circulam) pelas salas de aula e das quais participaram, de algum modo, da constituição do seu patrimônio, desde as décadas focadas até os dias atuais.

Para pensarmos a história das atuais Faculdades de Tecnologia do estado de São Paulo (Fatec), guiamo-nos por elementos que podem dar indícios da cultura produzida em tais instituições, apoiando-nos nas entrevistas realizadas com os professores de Matemática da Fatec de São Paulo e a de Ourinhos. Por meio dessas narrativas é possível construir, exclusivamente, uma breve história que captura aspectos do cotidiano escolar e traz à cena seus atores, bem como pode-se perceber uma multiplicidade de experiências, de significados, de sentidos próprios, em oposição à unicidade e à homogeneidade 
existente nos ordenamentos oficiais que caracteriza muitos estudos sobre instituições de ensino (GASPAR, 2010).

\section{0 que nos trazem as narrativas?}

No início dos anos de 1970, a Matemática (ou como encontramos em nossas narrativas, "as Matemáticas") apareceu pela primeira vez nos dois cursos técnicos de nível superior do então Centro Estadual de Educação Tecnológica de São Paulo, divididos, cada um, em modalidades: Construções Civis ("Edifícios", "Obras Hidráulicas” e "Movimento de Terra e Pavimentação") e Mecânica ("Desenhista Projetista" e "Oficinas”). Tratava-se da disciplina de Métodos de Cálculo, componente comum aos cursos implantados e sob a responsabilidade do professor Aníbal Callado (BROTI, 2012). Assim, “a Matemática passou a ter o Cálculo I, que se chamava Métodos de Cálculo"

Em 1974, o Conselho Estadual de Educação aprovou o curso de Técnico de Nível Superior em Processamento de Dados (PD), com a seguinte sugestão de grade curricular para a Área Técnica: 1. Linguagem e Técnica da Programação; 2. Matemática e Estatística; 3. Administração; 4. Sistema de Programação; 5. Análise de Projetos de Sistemas em Processamento de Dados; 6. Economia e Finanças; 7. Noções Gerais do Direito; 8. Recuperação de Informação; 9. Tópicos Avançados em Processamento de Dados; 10. Inglês. Para a Área de Humanidades foram destinados os estudos de "Língua Portuguesa", "Humanidades", "Relações Humanas e Direito Trabalhista" e "Estudo dos Problemas Brasileiros" (BROTI, 2012, p. 68).

O nosso curso de Processamento de Dados foi pioneiro, veio antes do curso da Unesp, de Bauru. Antes mesmo da antiga FEI. Assim, começou em 1974, o curso na Fatec. Quem veio montar esse curso foi uma moça que trabalhava na IBM e que se chamava Íris, se não me engano, ou Isis. Ela veio para cá, preparou o programa do curso, as disciplinas e tudo dentro daquilo que tinha que ser. O esboço do curso foi aprovado no Departamento, foi aprovado pela Congregação e foi transformado em curso. Só que o curso tinha uma concorrência monstruosa, nós chegamos a ter 55 candidatos por vaga. $\mathrm{O}$ pessoal terminava a Poli e fazia o PD, inclusive alunos da própria Politécnica. Chegou a ter uma sala com 20 alunos da Poli, no noturno, isso dos 60 alunos ingressantes, porque esse curso de PD era voltado para computadores de grande porte e as empresas, como os grandes bancos e a IBM, não tinham funcionários capacitados em tecnologia. O Serpro tinha uma dificuldade violenta de contratar funcionários para computadores de grande porte. Então, nós chegamos a ter aqui, por exemplo, um professor que hoje é diretor de todo o processamento de dados do grupo Itaú, só para se ter uma ideia da notoriedade da pessoa. Os nossos alunos egressos que adentravam no mercado de trabalho tinham salários melhores do que os nossos (Depoimento do professor Walter Paulette, neste trabalho). 
No curso de PD atuaram todos os nossos entrevistados, que também passaram por “diversas Matemáticas" implantadas ao longo dos cursos de tecnologia das Fatec. De certo modo concomitante, ocorrem o nascimento da informática no estado de São Paulo, a implantação dos cursos de Processamento de Dados nas faculdades do Centro Paula Souza e o surgimento "das Matemáticas" na tecnologia, ou seja, visando a atender cursos cujos alunos tinham (ou deveriam ter) perfil bastante diferenciado do perfil acadêmico usual no ensino superior, o olhar, agora, voltar-se-ia à prática, e não à pesquisa acadêmica. A Matemática ensinada não seria para matemáticos ou engenheiros, e sim para tecnólogos. Não se deveria ter a preocupação em formalizar demasiadamente a teoria a se ensinar, potencializando a capacidade necessária para que os alunos pudessem adquirir determinados conhecimentos em outras áreas. Esse objetivo da Matemática nas Fatec que alinhava a grande parte dos documentos que tivemos à mão - parece, segundo nossas apropriações, criar uma disciplina, ou o desejo por uma disciplina, cujo foco não deveria ser habilitar profissionais para o ensino e nem para um "saber sábio", ou seja, aquele destinado às pesquisas acadêmicas. Assim, as Matemáticas estariam restritas e fadadas a serem cursos de serviço, no caso, a serviço da tecnologia, o que futuramente ganharia respaldo, por meio da troca de experiência dos professores que participaram de intercâmbios, como o que ocorreu com a Alemanha, de um modelo de ensino que privilegiava a prática e a utilização do saber matemático como ferramenta para os alunos que alimentariam as indústrias e o setor produtivo.

O saber matemático, na vida dos professores de Matemática nas Fatec parece ter, sempre, se revestido de um duplo sentido e aspecto: o de ferramenta e o de objeto. Disponíveis funcionalmente certas noções e teoremas para a resolução de problemas e interpretação de questões pontuais, o saber matemático assumia o estatuto de "ferramenta" - um saber que normalmente não se constituía em objeto de estudo específico - e, enquanto dotado de elementos integrantes de um corpo científica e socialmente reconhecido, capazes de formular definições, enunciar e demonstrar teoremas, o saber matemático ganharia o status de "objeto" (MARANHÃO, 1999). Aos alunos das faculdades do Centro Paula Souza entendia-se como suficiente ter o saber matemático como ferramenta que pudesse ajudar em outras disciplinas nas quais os conteúdos de Matemática eram chamados à cena:

O saber deve ser construído e adquirido para que se possa mostrar a importância dos conteúdos, porque em determinados momentos e situações os alunos terão que dominar a ferramenta (...). Agora, o que eu vi na Alemanha, pois eu não fui para as IUTs da França, é que os professores estão preocupados 
em dar uma ferramenta para resolver problemas que interessem aos alunos, pois, em construção de máquinas, as equações diferenciais eram voltadas à prática (Depoimento do professor Kurata, nesta pesquisa).

O "saber sábio", aquele destinado às pesquisas acadêmicas, não foi (ou não deveria ser, segundo nossos depoentes) privilegiado nos cursos de tecnologia, pois a Matemática a ser ensinada tinha como finalidade auxiliar na pesquisa prática, cujos laboratórios de formação tecnológica se encontravam nas indústrias, nas fábricas, no mundo do trabalho. Portanto, criou-se uma cultura específica de disciplina: uma Matemática para tecnólogos. Melhor seria dizer que foi criado e circulou, nesse cenário, um discurso sobre a legitimidade e a necessidade - para determinados fins - de uma disciplina escolar específica: uma Matemática vinculada à Tecnologia. É importante reiterar a distinção entre a existência de uma tal Matemática Escolar e o discurso que lhe dá sustentação. Em boa parte, o discurso de sustentação é o que se torna, efetivamente, o objeto do qual o discurso trata, mas é também preciso, por cautela, considerar que em nossos depoimentos não há elementos suficientes para entender como essa Matemática específica frequentava o cotidiano das salas de aula, em meio a quais práticas, dirigida a quais finalidades, os conteúdos efetivamente ocorriam no dia a dia do ensino, como era avaliada no ritmo das Fatec essa suposta "nova matemática".

Essa diferenciação entre discurso e prática efetiva é tênue, fugidia, mas ainda assim é fundamental e extremamente significativa no contexto deste nosso trabalho. Havia claramente um discurso de sustentação a uma nova perspectiva quanto à Matemática Escolar - a de uma Matemática voltada à tecnologia. E a Matemática, nós sabemos, é um discurso manifestado em algumas práticas. $\mathrm{O}$ discurso que legitima essa "nova Matemática", porém, pode não ter sido efetivado nas salas de Matemática, ainda que essas salas estivessem orbitando num cenário em que as questões da tecnologia eram o principal foco. Assim, os professores de Matemática podem não ter efetivamente criado estratégias e práticas relacionadas a uma Matemática voltada à Tecnologia, ou seja, essa "nova" Matemática pode não ter sido objeto de ensino nas classes de Matemática, já que é muito usual que as aplicações - e mesmo as subversões - em relação à Matemática ensinada e aprendida em cursos específicos ocorram, via de regra, fora das salas de aula de Matemática. Ou seja, constituiriam, ainda assim, um objeto de ensino nesse cenário da formação tecnológica, mas não teriam nos professores de Matemática seus principais agentes de criação e desenvolvimento. Esse recorte deve servir para deixar claro que, ainda que sustentemos a existência de uma Matemática escolar específica nesse contexto, 
nossa pesquisa não tem elementos substanciais para enveredar, com profundidade, por essa Matemática e o modo como efetivamente os professores de Matemática participavam da constituição desse saber escolar.

No discurso dos professores, porém, é clara a afirmação de "a cada curso uma Matemática distinta”, com aplicações específicas e direcionadas aos objetivos da formação discente. Esse saber prático parece ter sido incorporado à cultura escolar das Fatec, tanto como meio de ampliar os conhecimentos matemáticos apropriados em níveis anteriores quanto por suas possibilidades de contribuir com uma formação profissional que pudesse ajudar no crescimento do país, apropriada às circunstâncias sociais.

Nesse sentido, as consequências sociais e políticas de tal especificidade levariam ao surgimento de um novo profissional no mercado de trabalho que, de modo emergencial, participaria do crescimento do país, tornando-o menos dependente das tecnologias e do know how de outros países. Como efeito concernente à tal cultura escolar, tem-se a cristalização de uma Matemática ensinada pautada - ao menos discursivamente - pelo viés prático, vinculada ao mundo do trabalho, e não um saber especificamente voltado à pesquisa acadêmica ou à matemática escolar "usual".

E, nessas faculdades de tecnologia existiam cursos específicos para mecânica e elétrica em três anos, formando um técnico avançado, um tecnólogo. Então, esse foi o modelo que foi copiado por Paula Souza. Agora, foi feito em dois anos por quê? Porque na época se pensava em velocidade, na possibilidade de se ter uma mão de obra rápida para o mercado, sem renunciar à qualidade. Eles optaram por cursos trimestrais, ou seja, um trimestre de aula, 15 dias de férias, outro trimestre de aula, 15 dias de férias, outro trimestre e não parava, o aluno ia direto, era extremamente pesado o curso. Eu diria que nesses 2 anos se via até mais do que se vê hoje em 3 anos (Depoimento do professor Chixaro, nesta pesquisa).

O tecnólogo, entretanto, passou a ser identificado como um profissional diferenciado em sua formação, em suas atribuições e ao papel que ocupava na sociedade, mas, muitas vezes, de modo paradoxal, em momentos de crise nos quais se restringia o mercado das profissões, o tecnólogo incomodava bacharéis e engenheiros, de perfil mais acadêmico.

A originalidade da cultura estabelecida nas faculdades de Tecnologia do estado de São Paulo acabou por constituir uma Matemática que traduziu os resultados estruturantes concorreu para edificar na cultura escolar diferenciada.

O saber deve ser construído e adquirido para que se possa mostrar a importância dos conteúdos, porque em determinadas momentos e situações os alunos terão que dominar a ferramenta (...). Agora, o que eu vi na Alemanha, pois eu não fui para as IUTs da França, é que os professores estão preocupados em dar uma ferramenta para resolver problemas que interessem aos alunos, 
pois, em construção de máquinas, as equações diferenciais eram voltadas à prática (Depoimento do professor Kurata, nesta pesquisa).

A importância das disciplinas escolares na conformação da cultura escolar fez

Chervel (1990) afirmar que:

Desde que se compreenda em toda a sua amplitude a noção de disciplina, desde que se reconheça que uma disciplina escolar comporta não somente as práticas docentes de aula, mas também as grandes finalidades que presidiram sua constituição e o fenômeno de aculturação de massas que ela determina, então a história das disciplinas escolares pode desempenhar um papel importante não somente na história da educação, mas na história cultural. Se se pode atribuir um papel "estruturante" à função educativa da escola na história do ensino, é devido a uma propriedade das disciplinas escolares. O estudo dessa leva a pôr em evidência o caráter eminentemente criativo do sistema escolar e, portanto, a classificar no estatuto dos acessórios a imagem de uma escola encerrada na passividade, de uma escola receptáculo dos subprodutos culturais da sociedade. Porque são criações espontâneas e originais do sistema escolar é que as disciplinas merecem um interesse todo particular. E porque o sistema escolar é detentor de um poder criativo insuficientemente valorizado até aqui é que ele desempenha na sociedade um papel que não se percebeu que era duplo: de fato ele forma não somente os indivíduos, mas também uma cultura que vem por sua vez penetrar, moldar, modificar a cultura da sociedade global (CHERVEL, 1990, p. 184).

Logo, quais foram os professores que participaram da criação da cultura matemática nas faculdades ao longo do nosso recorte temporal? Quais atores atuaram nas disciplinas de Matemática nas, pelas e para as faculdades do Centro Paula Souza, apoiando uma cultura talvez particular, capaz de interferir ou encontrar forte ressonância fora da instituição?

Por meio de nossas entrevistas encontramos vestígios de que o modelo de profissional aceito pela insituição pode ter tido uma influência muito grande sobre a prática pedagógica.

Eu acho o seguinte: o nosso grupo de matemáticos é um pouquinho fanático pela Matemática, sabe? Porque a gente vibra demais e participa demais, tem bastante diálogo e cumplicidade. Então, nessa época em que os alunos eram muito bons, eu passava a tarde inteira inventando exercícios para as provas, e os alunos eram bons e faziam provas bem puxadas e todo mundo tirava 10. Eu sempre esperava mais, eu podia fazer várias demonstrações, era um curso mais bem dado, mais bem aceito inclusive, porque eles conseguiam acompanhar. Tudo o que eu fazia antigamente eu não posso mais fazer atualmente (Depoimento do professor Walter Paulette, nesta pesquisa).

Nossos docentes participaram de atividades para além da sala de aula, trabalhando em bancos, fábricas e empresa comercial. Alguns professores (a maioria) abortaram, ao longo do tempo, a ideia de se tornarem bacharéis e migraram da engenharia para a docência da Matemática, iniciando-a em cursinhos preparatórios para vestibulares. Outros, vieram das licenciaturas ou dos bacharelados em Matemática. Em seus estudos de pós-graduação - e mesmo já atuando em salas de aula das faculdades do Centro Paula 
Souza -, quase a totalidade dos professores de Matemática passou por cursos que não eram destinados à docência. Defenderam dissertações e teses em que, na maioria das vezes, o foco não era a educação e, provavelmente, sofreram um conjunto de influências, crenças arraigadas de seus professores e da concepção pedagógica dominante na época: a Matemática era feita de verdades absolutas, era incontestável, valorizava-se excessivamente o contéudo transmitido por docentes moldados numa imagem rígida, tal qual a ciência "dura" que ensinavam.

Ao chegarem às Fatec, trouxeram experiências diversas: a da grande quantidade de conteúdos e técnicas de memorização dos cursinhos, os métodos e as metodologias de ensino de primeiro e de segundo graus da época, o rigor disciplinar do colégio de freiras ou da academia militar pelos quais transitaram.

Os professores recebiam uma programação aula por aula, estabelecendo, a priori, o que iriam trabalhar com os alunos e em determinado dia, sendo isso considerado pelos docentes como uma estratégia representativa de organização e da "engrenagem" do grupo. Sabiam o que seria dado na aula 1, na aula 2, até a décima oitava aula, até a trigésima sexta se fossem duas vezes por semana, até a centésima oitava quando três aulas por semana. As aulas eram rigorosamente planejadas "devido ao grupo ser muito unido, muito organizado" (segundo depoimento coletado para a pesquisa). Contudo, uma linha de trabalho havia sido estabelecida anteriormente pelo temido e severo professor Aníbal Callado: uma sequência de matéria pronta, como a dos modelos de racionalização do sistema de instrução programada (FIORENTINI, 1995).

No início dos cursos das faculdades do Centro Paula Souza havia escassez de material didático e de livros relacionados às disciplinas da área de Matemática. Foram adotadas algumas obras e tomados como referenciais para o preparo das aulas "das Matemáticas" livros como os de Mendelson, Castrucci, Stewart, Flemming e Gonçalves, Demidovitch ${ }^{3}$.

Com o passar do tempo e com a prática adquirida nas aulas dos cursos em que lecionavam, os professores de Matemática começaram a se reunir para a discussão de metodologias e de técnicas para a resolução de problemas matemáticos, além da elaboração de exercícios para as provas. De tais encontros resultaram a confecção dos

\footnotetext{
${ }^{3}$ MENDELSON, E. Introduction to Mathematical Logic. Boston: Springer, 1987; CASTRUCCI, B. Introdução à Lógica Matemática. São Paulo: Editora Nobel, 1975; STEWART, J. Cálculo. Volume 1. 6. ed. São Paulo: Cengage Learning, 2009; FLEMMING, D. M.; GONÇALVES, M. B. Cálculo A. 6. ed. São Paulo: Pearson, 2012; DEMIDOVICH, B. P. Problemas e exercícios de análise matemática. Moscou: Editora Escolar - MIR, 1977.
} 
próprios materiais didáticos e livros utilizados em sala até os dias atuais nas Fatec e, inclusive, em outras instituições de ensino tecnológico.

As apostilas originárias das reuniões do grupo e confeccionadas na própria Fatec São Paulo foram utilizadas principalmente para a resolução de exercícios, característica de um método que valorizava a técnica e a instrução programada, ou seja, o aluno adquiria conhecimento pela experiência, tendo como base princípios da racionalidade, eficiência e produtividade, desenvolvendo agilidade por meio de treinos de conteúdos selecionados e transmitidos pelo professor.

Em relação às disciplinas ministradas, adotamos referências nacionais, fazíamos nossas apostilas aqui, desenvolvíamos as apostilas. Também existiam alguns livros básicos, naquela época não havia muita bibliografia (Depoimento do professor Jaques, nesta pesquisa). 
Figura 1: Lista de Cálculo II - Prof. Syozo Yamazato



Fonte: Apostila n ${ }^{\circ} 49$ - Adaptada pelos Autores (2021)

A prescrição do método apostilado preparava os alunos para a obediência a padrões, com esquemas e "macetes" voltados às aplicações e repetições (Figura 1). Não havia a obrigação de se fazer demonstrações e o ensino era mais voltado a operações

Logo, a finalidade do ensino da Matemática, na tendência tecnicista, seria a de desenvolver habilidades e atitudes computacionais e manipulativas, capacitando o aluno para a resolução de exercícios ou de problemas-padrão. Caberia à escola preparar recursos humanos "competentes" tecnicamente para este sistema (FIORENTINI, 1995). 
Sob a responsabilidade dos professores de Matemática do Centro Paula Souza, metodologias e materiais didáticos foram pensados e adotados como modelos para serem aplicados e manipulados de modo a "facilitar a aprendizagem".

\begin{abstract}
Assim, aprendi a dar aula com ele, e eu ainda me lembro até hoje do saudoso professor Callado. Ele sempre dizia que eu era matemático, mas que estava dando aula não para matemáticos, e sim para um curso de tecnologia, portanto, de tecnólogos. Nós tínhamos uma formação e uma visão de aula estritamente da Matemática e estávamos atuando num curso de tecnologia” (Depoimento do professor Kurata, nesta pesquisa).
\end{abstract}

Assim, principalmente as apostilas confeccionadas pelos professores de Matemática eram um dos elementos materiais considerados adequados para o ensino da disciplina, de modo a organizar a aprendizagem, resolver problemas, exercitar o raciocínio e permitir que os docentes acompanhassem a produção dos saberes. As apostilas poderiam ser consideradas como um instrumento de trabalho e de controle tanto do aluno como do professor no cumprimento do programa de ensino. Tais artefatos materiais não eram destituídos de neutralidade e respondiam a determinadas intenções e necessidades, podendo fornecer dados sobre a peculiaridade da vida escolar (SOUZA, 2007, p. 71).

Parece-nos que, ao longo da sua atuação, "o grupo da Matemática” adquiriu certa autonomia para pensar sobre o ensino da disciplina, confeccionando seu próprio material e métodos, adquirindo os livros que julgavam importantes para manter o status da disciplina, realizando estratégias para que o vestibular se tornasse ainda mais seletivo, já que as provas elaboradas pelo grupo eram difíceis, ou ainda, participando de reestruturações que contemplavam a inclusão de disciplinas de Matemática nos cursos. Também coube ao "grupo da Matemática" ajudar na criação de um lugar institucional visto pela sociedade e, até mesmo pela imprensa, como destacado principalmente devido à concorrência, além de sua excelência na qualidade de ensino.

A visão passado-presente dos nossos professores de Matemática traz um exacerbado saudosismo dos "bons alunos" da época, da Matemática que era mais "pesada", das mudanças de conteúdo, das grades curriculares que contemplavam as disciplinas, atribuindo o fracasso do ensino atual da Matemática nas faculdades aos níveis anteriores do sistema escolar. Trata-se da eterna concepção de que a escola de antes era melhor.

Naquela época o conteúdo era bem mais aprofundado. O cálculo que víamos na Matemática 1 e na Matemática 2 contemplava mais as teorias, e hoje, parece-me que está bem resumido e voltado apenas para as noções e pronto. Eu acho isso também muito ruim porque faltam elementos depois para o nosso 
aluno enfrentar problemas lá fora e que poderiam ser resolvidos por meio da ajuda da ferramenta matemática estudada. Sinto um desequilíbrio muito grande nas disciplinas da área de Matemática quando comparadas ao meu início na Fatec e, no decorrer desses 24, 25 anos em que estou atuando na docência, vejo que isso acaba interferindo de modo direto em outras matérias técnicas. Em Programação escutamos muito os professores reclamando da falta da "lógica matemática” (Depoimento do professor Sidney Ferrari, nesta pesquisa).

Parece-nos que o argumento apresentado pelos professores é próprio da cultura escolar do ensino de Matemática, mostrando-se também, de forma clara, nos discursos dos docentes das Fatec. Refere-se ao pensamento linear que impera nessa cultura sobre o ensino da disciplina. Há sempre de se buscar um pré-requisito para provocar o desencadeamento e uma sequência de forma linear que justifique o sucesso ou fracasso dos níveis ascendentes de ensino:

(...) na época, os alunos vinham bem preparados, eram alunos que tinham feito um bom ensino, um ensino médio público, que era o melhor. Esses alunos conseguiam acompanhar a grade destinada à Matemática. No primeiro ano de Matemática se via limite, derivada, cálculo de integral e se chegava a equações diferenciais. Coisa que hoje nem pensar.... Hoje eu diria que o curso de Matemática foi reduzido a uns $10 \%$ do que ele já foi dentro das faculdades. Ah! A matemática ensinada era bem diferente de hoje. Era bem mais matemática, era uma formação mais pesada em Matemática (Depoimento do professor Chíxaro coletado para a pesquisa).

Diante de toda complexidade que envolve a criação de uma disciplina escolar, não se constituindo como tal do dia para a noite e nem desprovida de lentidão, precaução e segurança, há também renovações constantes e mudanças para atender a seus públicos escolares. De acordo com Chervel (1990), tal visão não ocorre no sistema superior, cuja característica fundamental é a de transmitir diretamente o saber, coincidindo as práticas com as finalidades, ou seja, o mestre ignora a necessidade de adaptar a seu público os conteúdos, tornando-o invariante.

Não obstante, apesar de nossos professores não perceberem que "as disciplinas são o preço que a sociedade deve pagar à sua cultura para poder transmiti-la no contexto escolar" (CHERVEL, 1990, p. 222), e que há transformações de conteúdo, de estrutura, em função das exigências de novas realidades, de estudos e de pesquisas em diversas áreas do conhecimento, os docentes entrevistados criaram estratégias para acolher os alunos ingressantes que mostravam/mostram dificuldades nas disciplinas de Matemática, numa tentativa de organização e contraposição à realidade e à negatividade da precariedade que eles apontam no ensino dos níveis anteriores da escolaridade.

Teoricamente formados em meio a tendências tradicionais de ensino baseadas em um método que privilegiava a quantidade de conteúdos transmitida pelo professor, figura central do processo de ensino e aprendizagem, nossos depoentes parecem, a partir de seus 
discursos, terem usado criatividade e proposto inovações para o ensino da Matemática, como as aulas de reforço e nivelamento - até hoje ministradas em horários diferenciados aos da carga horária oficial dos cursos -, o laboratório de Matemática - onde os alunos fazem seus experimentos e validações teóricas, e o uso da História da Matemática nas aulas de Cálculo, característica incomum aos cursos de tecnologia (mesmo que, em muitas vezes, esse uso seja assumido como possibilidade de salvaguardar o aprendizado da disciplina).

Foram criados, também, locais específicos para "a prática das Matemáticas", como os centros de pesquisas estatísticas e empresas que oferecem estágios e apoio à comunidade, com várias frentes de estudos que envolvem a Matemática, a Estatística e a Computação.

$\mathrm{O}$ discurso que de a educação tecnológica deve ser diferente da educação acadêmica tem sobrevivido nas faculdades de Tecnologia do estado de São Paulo e tem ainda sustentado a bandeira de que os estudos que interessam aos cursos de tecnologia devem ser aqueles destinados ao mundo do trabalho, o que levou mais fortemente os professores a criar estratégias dentro das próprias faculdades do Centro Paula Souza.

\section{Arrematando...}

Todas as narrativas a que tivemos acesso nos ajudam a criar uma história das Faculdades de Tecnologia do estado de São Paulo consoante, em termos gerais, àquela registrada em documentos que consultamos antes das entrevistas (para orientar nossa interlocução com os depoentes) e/ou depois das entrevistas (para cotejar versões ou buscar detalhamentos).

Os depoimentos que nossos colaboradores compartilharam conosco, no entanto, mais especificamente, nos dão perspectivas subjetivas e exclusivas, falam das sensações dos professores em seus embates para cursar programas pós-graduados numa instituição em que a pesquisa não era vista como prioritária; contam das alterações curriculares, dos programas e legislações da época e como perceberam/percebem a situação dos que ingressam nas faculdades de tecnologia, comparando esses ingressantes com turmas anteriores, num discurso em que não se pode deixar de notar um certo saudosismo que enaltece a formação passada face à formação do presente, principalmente aquela das escolas de nível médio. 
É ainda importante ressaltar que os depoimentos, além desses fatores subjetivos que não podem ser encontrados em outros documentos, também trazem informações que não estão - ou que dificilmente são encontradas - nos arquivos escolares, como as práticas informais de contratação, que dispensavam concursos e se baseavam em indicações de professores mais antigos da casa, ainda que bastante comuns nos inícios de muitas instituições, mas que só podem ser apontadas a partir dos depoimentos dos que vivenciaram essas práticas.

Assim, é no conjunto das fontes disponíveis e nas fontes criadas com as entrevistas que conseguimos compreender um pouco da história das Faculdades de Tecnologia do estado de São Paulo e do vínculo dos professores de Matemática, de suas práticas e do lugar ocupado pela disciplina nessa instituição, percebendo claramente, entre os professores de Matemática das Fatec, um discurso favorável a uma nova Matemática, um discurso que legitima uma Matemática diferente, uma Matemática própria aos saberes tecnológicos, uma cultura matemática escolar específica.

De outro modo, a partir dos depoimentos de nossos professores cria-se a possibilidade de um debate e de uma história relativa ao ensino, às práticas, à formação profissional e ao lugar ocupado pela Matemática nos cursos superiores de tecnologia nas Fatec.

\section{Referências}

BOLIVAR, A.; DOMINGO, J.; FERNÁNDEZ, M. La investigación biográfico-narrativa en educación: enfoque y metodología. Madrid: La Muralla, 2001.

BRASIL. MEC. Centenário da rede federal de educação profissional e tecnológica. Brasília, 2009. Disponível em: http:// portal. mec.

gov.br/setec/arquivos/centenario/historico_educacao_profissional.pdf. Acesso em: 15 ago. 2016.

BROTI, M. P. O Ensino Superior no Centro Estadual de Educação Tecnológica Paula

Souza: sujeitos, experiências e currículo (1969-1976). 2012. Dissertação (Mestrado em Educação: História, Política, Sociedade) - Pontifícia Universidade católica de São Paulo, São Paulo, 2012.

CHERVEL, A. História das disciplinas escolares: reflexões sobre um campo de pesquisa. Teoria \& Educação, Porto Alegre, v. 2, n. 2, p. 177-229, 1990.

CURY, F. G. Uma história da formação de professores de Matemática e das instituições formadoras de estado de Tocantins. 2011. Tese (Doutorado em Educação Matemática) Instituto de Geociências e Ciências Exatas, Universidade Estadual Paulista, Rio Claro, 2011. 
FIORENTINI, D. Alguns modos de ver e conceber o ensino da matemática no Brasil. Zetetike, Campinas, v. 3, n. 1, p. 1-16, out. 1995. Disponível em: https://periodicos.sbu.unicamp.br/ojs/index.php/zetetike/article/view/8646877/15035. Acesso em: 05 mar. 2021.

GARNICA, A.V.M. Sobre Historiografia: fragmentos para compor um discurso. REMATEC, Natal, v. 8, n. 12, p. 51-65, jan./jun. 2013.

GASPAR, V. História, Educação e Cultura Escolar. Revista Pedagógica, Chapecó, v. 2, n. 25 , p. 313-323, jul./dez. 2010.

MARANHÃO, M. C. S. A. Dialética Ferramenta Objeto. In: MACHADO, S. A. D. (org.). Educação Matemática: uma introdução. São Paulo: EDUC, 1999. p. 115-134.

MOTOYAMA, S. Educação Técnica e tecnológica em questão. 25 anos de CEETEPS: uma história vivida. São Paulo: Unesp, 1995.

MOTTA, R. P. S. As universidades e o regime militar: cultura política brasileira e modernização autoritária. Rio de Janeiro: Zahar, 2014.

SILVA, F. C. A faculdade de tecnologia de sorocaba: antecedentes e primeiros anos (1971 1981). 2008. Dissertação (Mestrado em Educação) - Faculdade de Educação, Universidade de Sorocaba, Sorocaba, 2008.

SOUZA, R. F. de. DOSSIÊ. Vestígios da cultura material escolar. Revista Brasileira da História de Educação, Campinas, v. 7, n. 14, p. 11-14, maio./ago. 2007. Disponível em: http://www.rbhe.sbhe.org.br/index.php/rbhe/article/view/127/0. Acesso em: 25 nov. 2017.

TAIRA, L. Relações Históricas no Universo da Fatec-SP: técnica -tecnologia-educação. 2005. Tese (Doutorado em História Social) - Departamento de História, Faculdade de Filosofia, Letras e Ciências Humanas, Universidade de São Paulo, São Paulo, 2005.

Recebido em: 22 de janeiro de 2021. Aceito em: 02 de março de 2021. 